\title{
REPORT OF COMMITTEE ON THEORETICAL RESEARCH IN HEREDITY.
}

By Charles W. Ward, Queens, N. Y.

Your committee has found itself scarcely prepared to render a complete report upon the subject. The laws governing the transmission of hereditary traits are not at present sufficiently well understood to warrant the committee in recommending any theory or set of theories for experimenters in this field to follow.

There is, however, sufficient material now in existence to guide the student in heredity research well into the field and to give him certain tangible facts as starting points. The field is so broad and the ramifications of the subject are so intricate and profound that there is ample room for many groups of investigators interested in demonstrating nature's laws governing the reproduction of species to follow out special lines of research work with a probable certainty that each group of workers will secure valuable information, the compilation of which will in the end prove of immense benefit to the human family.

It will be admitted by all that any information tending to aid the human being to bring forth improved offspring will prove of inestimable value to the race as soon as it can be transmitted to the thinking public and a sufficient number of people can be impressed with the benefits to be derived therefrom to induce them to put it in practice and afford practical living demonstration of the soundness of the theories advocated.

For instance, if Redfield's doctrine that " the great mass of criminals and prostitutes are recruited from children born of parents ranging from 16 to 20 years of age at the time of the birth of the children" can be accepted as proven, we then have a positive reason for discouraging youthful marriages, or even prohibiting them by law, and could we bring the mass of people to understand and appreciate the importance of foregoing marriage until a certain safe degree of maturity has been attained, we might thereby greatly reduce the number of immature marriages and consequently reduce the percentage of births of children congenitally inclined to crime. Such a reduction would thus contribute directly to raising the average of moral excellence of the mass of the human race.

Again if the doctrine of "use inheritance" can be demonstrated, and it shall come to be known to be a fact that great scholars, great musicians, and others distinguished on account of their powerful intellects are mainly children born of mature parents, after such parents had cultivated within themselves by years of study, use, and practice the very attributes which they transmitted to their offspring we would have clearly pointed out a practical way to improve the human offspring by limiting the time of conception and birth to that period of life and to those conditions in which the parents are best fitted to 
produce the desired type of offspring. Thus, this adoctrine could well be invoked in the production of any type of human being, whether scholar, artisan, or laborer, and the same doctrine could also be invoked as well to prevent the production of offspring from mature confirmed criminals.

Unfortunately the evidence in favor of these theories is as yet too meagre to allow of safe deductions. It is greatly to be desired that more extensive careful research be conducted on the subject of heredity in human beings, and it is of the highest importance that such research be conducted by carefully trained conservative investigators. No more attractive field of study and speculation exists in the whole realm of human thought and activity than that of heredity in man, and as a result many writers wholly unprepared by training and experience have studied and written on this subject. Erroneous doctrines attractively presented might be very injurious, and the inexperienced reader has no way to distinguish between the good and the bad. The Committee on Heredity consider that it is one of their functions to become familiar with the literature bearing on the subject of human heredity, and wherever books and papers appear which treat the subject in a conservative and safe way, recommend them to the consideration of the reading public. Such recommendations, however, cannot be made in the present report.

The principles of heredity can doubtless be worked out more readily by investigation with animals and plants than with man, and as the same principles apparently hold good in general throughout the organic world, it would seem that at the present time what is most needed is carefully planned experiments with plants and animals where large numbers can be used and where the parentage can be controlled. Indeed, it is in the breeding of plants and animals that any new principle discovered will be applied promptly and have its greatest immediate value. It would require years for the knowledge of such a principle to become sufficiently general to materially infiuence the human species, even if it is capable of being adopted in this capacity.

Mendel's laws or principles of heredity which have attracted such widespread attention require to be studied more thoroughly and critically. The limitations of Mendelian characters are yet very imperfectly understood, and there is need in this field for research on many widely different plants and animals of both wild and domestic varieties and species.

The mutation theory of Dr. Vries has also opened to the student of heredity and breeding a new and fertile field of experimental research. The study of mutations and otber types of variations and their hereditary strength and importance in the formation of varieties and species. is of the utmost importance. It seems probable from recent researches that mechanical means may be used to force such variations, and if such methods can be devised they would be of great aid to the practical breeders of plants and animals. Throughout the recent literature on heredity, Mendel's law and the mutation theory, the conception of 
unit characters represented probably by some tangible protoplasmic unit which is transmissible from cell to cell and in sexual unions has become a dominant idea. It is very important that careful cytological studies be made of hybrids and their parents and of mutations, to determine so far as possible the protoplasmic mechanism of heredity. It will be the aim of the Committee on Heredity to encourage work on the various important problems and from time to time present papers summarizing the knowledge on the various important factors.

Appended to the present report are short statements regarding some of the important problems by Dr. C. B. Davenport and Professor W. J. Spillman, which are submitted for publication following this report. Respectfully submitted,

C. W. WARD, Chairman of Committee.

\section{RECENT ADVANCES IN THE THEORY OF BREEDING.}

By Dr. Charles B. Davenport, Cold Spring Harbor, New York.

The new era in theoretical breeding opened in 1900 with the rediscovery of Mendel's law. At the same time something even more important was diaclosed; namely, that Devries, Porrens, Tschermak, Spillman and still others were already advanced in extensive, accurate, and even statistical studies of inheritance in plants and animals. The rediscovery of Mendel's law was no accident; it was the necessary consequence of the new studies, and similarly these new investigations were the natural growth of a time fully ripe for them.

The apparent difficulties of pedigree breeding had deterred many scholars who realized its importance from attempting it, but after the task was actually undertaken its difficulties were seen to have been overestimated. At the present time even in universities, where there is no school of agriculture, excellent work in breeding is being done, for instance by Devries at Amsterdam; by Bateson and his pupils at the University of Cambridge, England; by Correns at the University of Leipsic; by Cuenot at the University of Nancy; and in America by Castle at Harvard, by Morgan and Crampton at Columbia, by Whitman and Tower at Chicago, by Moenkhaus at Indiana, and by Kellogg and Miss MacCracken at Stanford. Pedigree breeding at the nonagricultural universities has developed greatly in the last five years, a fact that promises well for the future.

The agricultural schools are at last awakening to their opportunity to contribute to research on the laws of heredity. Abroad such work is being done by Tschermak at the Agricultural College of Vienna, by Plate at Berlin, by Toyama at Tokyo; and in this country by Gowell at Maine, Rice at Cornell, and Erf at Kansas, all working with poultry, and by scores of others working with various groups of animals and plants. Nor must we overlook the numerous independent seientific. breeders, like Alexander Graham Bell on his Nova Scotia sheep farm. 